\title{
Comparison of two methods of irrigant agitation in the removal of residual filling material in retreatment
}

\section{Clarissa Teles RODRIGUES(a) Marco Antonio Hungaro DUARTE ${ }^{(a)}$ \\ Bruno Martini GUIMARÃES(a) Rodrigo Ricci VIVAN(a) Norberti BERNARDINELI(a)}

(a) Universidade de São Paulo - USP, Bauru School of Dentistry, Department of Dentistry, Endodontics and Dental Materials, Bauru, SP, Brazil.

Declaration of Interests: The authors certify that they have no commercial or associative interest that represents a conflict of interest in connection with the manuscript.

\section{Corresponding Author:}

Clarissa Teles Rodrigues

E-mail: clarissateles@usp.br

https://doi.org/10.1590/1807-3107BOR-2017.vol31.0113

Submitted: April 13, 2017

Accepted for publication: Oct 10, 2017

Last revision: Nov 23, 2017
Abstract: The aim of this study was to compare the efficacy of passive ultrasonic irrigation and EasyClean for removing residual filling material in retreatment. Twenty-two maxillary lateral incisors with apical curvature were instrumented with ProTaper files and filled with Endofill using the lateral compactation technique. Removal of filling material was performed with Reciproc, Mtwo and ProDesign Logic 50/.01 files. The teeth were inserted in a silicone mould, which was placed in a metal muffle, and split to visualize the residual filling material. The samples were divided into two groups $(n=11)$ according to the irrigation protocol: Passive ultrasonic irrigation (PUI group) with 3 activations of 20 seconds and EasyClean (Easy Equipamentos Odontológicos, Belo Horizonte, Brazil) (EC group) used in continuous rotation with 3 activations of 20 seconds, both using $\mathrm{NaOCl}$ and EDTA. Environmental scanning electron microscopic images of the apical, middle, and cervical thirds were taken before and after the irrigant activation. The Kappa test was used to determine interexaminer agreement. Statistical analysis was performed using Kruskal-Wallis, Mann-Whitney, and Wilcoxon tests $(p<0.05)$. PUI and EC improved the removal of remnant filling material in all root canal thirds $(p<0.05)$. PUI and EC presented similar performance in the final step of retreatment $(p>0.05)$. No significant difference was observed in the removal of filling material in the apical, middle, and cervical thirds in both groups $(p>0.05)$. EasyClean in continuous rotary motion is useful in retreatment and was shown to be as effective as ultrasonic activation in the removal of remnant filling material.

Keywords: Retreatment; Root Canal Irrigants; Root Canal Obturation.

\section{Introduction}

During endodontic retreatment, removal of filling material can be challenging because remnants of filling material persist irrespective of the technique and instruments used. . $^{1,2,3,4,5}$ Removal of these remnants is more difficult in the apical portion of the root canal or in the presence of curvatures. $2,3,4,6,7,8,9$ However, the complete removal of filling material is ideal because it allows for better disinfection through the action of the irrigating solution and better adaptation of the new filling material to the canal walls. ${ }^{2}$ 
Irrigation of the root canal provides both mechanical flush of debris and chemical action of the solution. ${ }^{10}$ Nevertheless, the flushing action from syringe irrigation is not sufficient to remove debris from the root canal. . 11,12 Therefore, several irrigation activation techniques have been proposed to improve the efficacy of irrigating solutions by promoting continuous movement of the irrigants. ${ }^{40,10,13,14,15,16,17,18}$

Passive ultrasonic irrigation (PUI) is the activation of an irrigant using an oscillating instrument placed in the center of the root canal, which induces acoustic streaming and/or cavitation of an irrigant. It has been used to improve the cleaning of the root canal space by increasing disinfection, smear layer and debris removal, even in hard-to-reach anatomical areas. . $^{10,11,15,19}$

Recently, a new agitation device called EasyClean (Easy Equipamentos Odontológicos, Belo Horizonte, Brazil) has been introduced. It consists of an acrylonitrile butadiene styrene (ABS) plastic instrument, which has a size of 25/.04 and an "aircraft wing" shaped cross section and is recommended for use in reciprocating motion. ${ }^{18}$ A previous study showed that compared to PUI, irrigant agitation with EasyClean promotes cleaner walls by removing debris in the apical portion of curved canals. ${ }^{18}$ Although the manufacturer suggests its use in reciprocation motion, it is speculated that the use of EasyClean in continuous rotary movement at low speed produces turbulence of the irrigating solution, favoring root canal cleaning. Recently, it was demonstrated that when EasyClean is used in continuous rotation for irrigant agitation, more efficacy in cleaning the isthmus area and root canal walls was achieved compared to its use in reciprocating motion..$^{20}$

The role of irrigant agitation in retreatment is controversial. ${ }^{21}$ Although some researchers reported that PUI did not improve the removal of filling material in curved canals, ${ }^{22}$ it has been reported that the use of PUI in retreatments enhances removal of filling material remnants after the reinstrumentation. ${ }^{25,5,6}$ The EasyClean system cleans by agitation of the irrigant and by mechanical drag of adhered debris, with the advantages of promoting agitation along the whole length of the instrument, with no risk of deforming the canal walls because unlike an ultrasonic tip, it is made of plastic. ${ }^{18}$ However, there is no study regarding the efficacy of EasyClean in the removal of filling material from the root canals in retreatment.

The aim of this study was to compare the use of PUI and EasyClean used in a rotary movement in the removal of residual filling material from curved canals during retreatment. The null hypothesis was that there would be no significant difference in filling material removal between ultrasonic activation and the use of EasyClean.

\section{Methodology}

\section{Teeth selection and root canal preparation and filling}

The sample calculation was performed using the G*Power v3.1 for Mac (Heinrich Heine, Universität Düsseldorf) by selecting the Wilcoxon-Mann-Whitney test of the t-test family. The data of a previous study of retreatment that used uniradicular teeth ${ }^{23}$ were used, and the effect size in the present study was established $(=1.60)$. The alpha type error of 0.05 , a beta power of 0.95 , and a ratio $\mathrm{N} 2 / \mathrm{N} 1$ of 1 were also stipulated. A total of 8 samples per group were indicated as the ideal size required for noting significant differences. Eleven samples were used, considering a 30\% risk of sample loss.

Ethical approval was granted by the local institutional ethics committee (protocol no. 075792/2016). Sixty-five maxillary lateral incisors with completely formed apices were used in this study. The teeth were digitally radiographed and canal curvatures were measured in buccolingual and mesiodistal directions according to Schneider's method ${ }^{24}$ and twenty-two teeth presenting apical curvature between $20^{\circ}$ and $35^{\circ}$ were selected. Coronal access was performed using diamond burs. A 10 K-file was introduced until its tip was visible at the apical foramen and the working length was set $1.0 \mathrm{~mm}$ short of this measure. The canals were prepared with ProTaper Universal (Dentsply Maillefer, Ballaigues, Switzerland) up to F1 instrument using an X-Smart electric motor (Dentsply Maillefer) at $300 \mathrm{rpm}$. Irrigation was performed with $1 \mathrm{~mL}$ of $2.5 \%$ sodium hypochlorite and a final rinse with $5 \mathrm{~mL}$ of $17 \%$ EDTA for 3 minutes. The root canals were flushed with saline solution, dried with paper points and obturated by the lateral compaction of gutta-percha cones and 
Endofill sealer (Dentsply Ind Com Ltda, Petrópolis, Brazil). Buccolingual and mesiodistal radiographs were taken to confirm the quality of canal fillings. Coronal accesses were sealed with temporary filling material (Coltosol; Coltene-Whaledent, Cuyahoga Falls, $\mathrm{OH}$ ), and the teeth were stored at $37^{\circ} \mathrm{C}$ and $100 \%$ humidity for 30 days to allow complete setting of the sealer.

\section{Retreatment}

For retreatment procedures, all specimens were prepared by the same operator with the aid of an operating microscope (M900; D.F Vasconcellos, Valença, Brazil) at X5 magnification. For each sample, the removal of filling material was performed in three steps: first, fillings were removed using R25 Reciproc files (25/.08) (VDW, Munich, Germany) with the respective Reciproc program of the VDW Silver electric motor; second, reinstrumentation was performed with Mtwo rotary files size 40, 0.04 taper (VDW) using the respective Mtwo 40/.04 program of the VDW Silver electric motor; third, another reinstrumentation was carried out with ProDesign Logic 50/.01 rotary files (Easy Equipamentos Odontológicos) size 50, 0.01 taper, used at $350 \mathrm{rpm}$ and $1.5 \mathrm{~N} / \mathrm{cm}$ torque. For both reciprocating and rotary files, a brushing motion against the canal walls was used after reaching the working length, until no visual evidence of residual filling materials could be seen and the canal walls were smooth. Before beginning root filling removal, an aliquot of $0.5 \mathrm{~mL}$ of orange oil solvent (Citrol, Biodinâmica, Ibiporã, Brazil) was put into the pulp chamber for 2 minutes to soften the gutta-percha. The solvent was not used in the subsequent steps of instrumentation.

\section{Sample preparation for environmental scanning electron microscopy}

After retreatment procedures, the teeth were decoronated and two longitudinal grooves were made in buccal and palatal walls with a diamond disc to facilitate the root split. Before splitting the roots, the samples were embedded in a two-piece metal muffle containing silicone material (Figure 1). A silicone mould was made inside the muffle to allow the teeth to be inserted in the same position during the irrigation protocol, without extruding the irrigants. Thus, the samples could be analyzed before and after the irrigation protocol to compare the removal of filling material remnants. After the silicone set, the muffle was disassembled, the teeth were removed and the roots were split by applying a vertical force using a 24 spatula. To choose the half with the greater amount of remnant filling material, both halves were viewed under a stereomicroscope (Stemi 2000C; Carl Zeiss, Jena, Germany) at a magnification of 5.5X. For assessment of filling material removal,
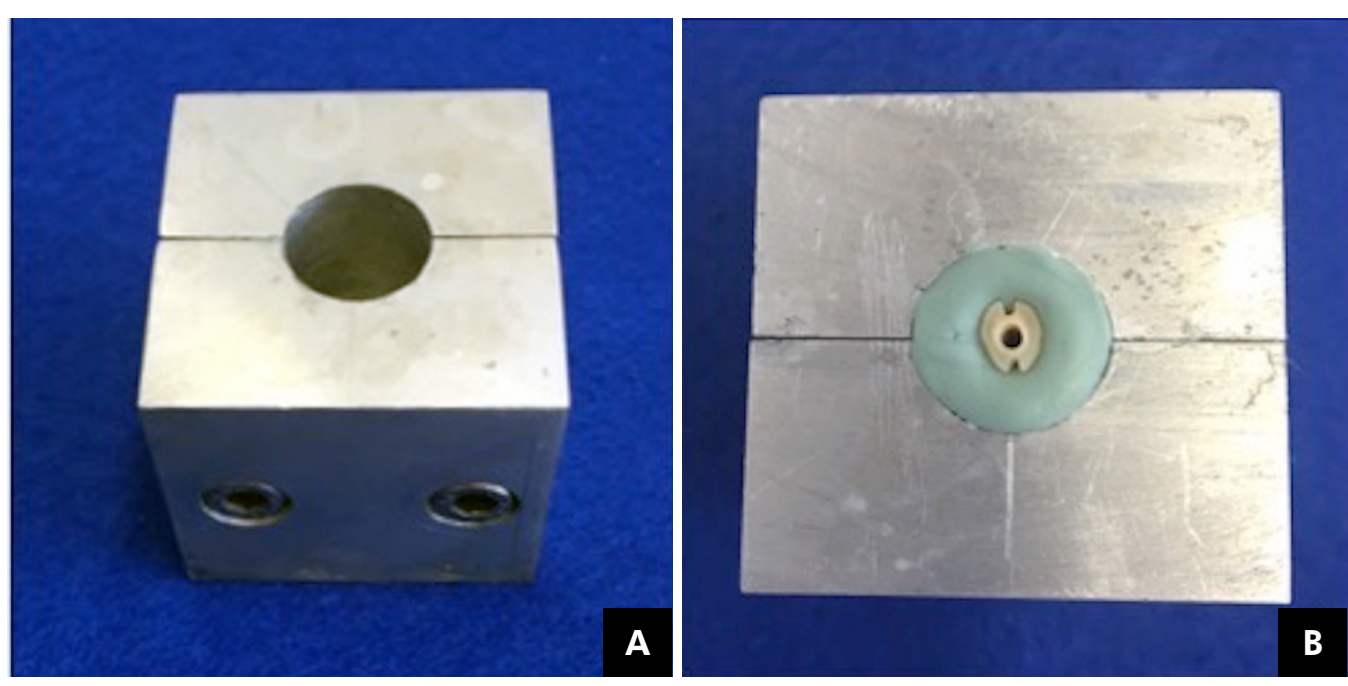

Figure 1. (A) Two-piece metal muffle used to make the silicone mould. (B) Sample inserted in the silicone mould to allow the two halves to reassemble before and after the irrigant activation. 
three areas were determined for each selected half of the teeth, in order to represent the cervical, middle and apical portions of the root canal. With a $1 / 4$ high-speed bur, three marks were made lateral to the root canal in the selected half of the teeth, to define the position of apical, middle and cervical thirds during image acquisition. Therefore, it was possible to analyze the filling material removal in the different levels of the root canal and compare the cleanliness of the same region before and after the activation procedure. Preoperative images of apical, middle and cervical thirds were taken by environmental scanning electron microscopy (Aspex Express; Fei Europe, Eindhoven, Netherlands) at an accelerating voltage of $15-20 \mathrm{kV}$ and a standard magnification of 750X. Statistical analysis using the Mann-Whitney test was performed using all the preoperative images in order for the samples to be divided into two groups according to the amount of filling material. This procedure allowed for the homogeneity of the samples between the groups because no significant difference was observed regarding the amount of remaining filling material between the two groups.

\section{Irrigant activation}

The teeth were placed in the silicone moulds and mounted in the muffle, and the irrigation activation protocol was performed for the different experimental groups as follows:

PUI Group ( $\mathrm{n}=11)$ : passive ultrasonic irrigation using an ultrasonic E1-Irrisonic Tip with size 20, 0.01 taper and no cutting blades (Helse Dental Technology, Santa Rosa de Viterbo, Brazil), mounted on an ultrasonic unit (NSK multi-task ultrasonic system; Nakanishi Inc., Tochigi, Japan) set to power 2. The ultrasonic activation was performed as described by Sluis et al. ${ }^{10}$ The ultrasonic tip was placed $1 \mathrm{~mm}$ short of the working length and activated by 3 cycles of 20 seconds, totaling 1 minute with each irrigating solution. The solutions used during the activation were $5 \mathrm{~mL} 2.5 \% \mathrm{NaOCl}, 5 \mathrm{~mL}$ 17\% EDTA and 1.0\% NaOCl, respectively. The irrigating solution was renewed each time a cycle of 20 seconds was performed. After this activation protocol, a final flush with $5 \mathrm{~mL}$ of saline was performed with no activation.
EasyClean Group ( $\mathrm{n}=11$ ): continuous irrigant activation using EasyClean, coupled to a micromotor and a contra-angle, in low speed, at approximately 20,000 rotations per minute (KaVo Kerr Group, Charlotte, USA). The EasyClean tip was placed $1 \mathrm{~mm}$ short of the working length and the same sequence of the irrigating solutions and irrigation times described for the PUI group was used.

The halves were removed from the moulds and taken to the environmental scanning electron microscope for postoperative imaging. All images were saved in a digital file (TIFF format) and loaded into the Microsoft PowerPoint software (Microsoft Corporation, Redmond, USA). To quantify the residual filling material, the images were divided into 100 square by using a digital grid. Each square represented an area of $27.5 \times 27.5 \mu \mathrm{m}^{2}$ (Figure 2). The number of squares with visible dentinal tubules, i.e., without residual filling material, was calculated by placing the digital grid over the images displayed in slide format on an LCD monitor. Two single examiners, previously calibrated and blind to the study, classified preirrigation and postirrigation images.

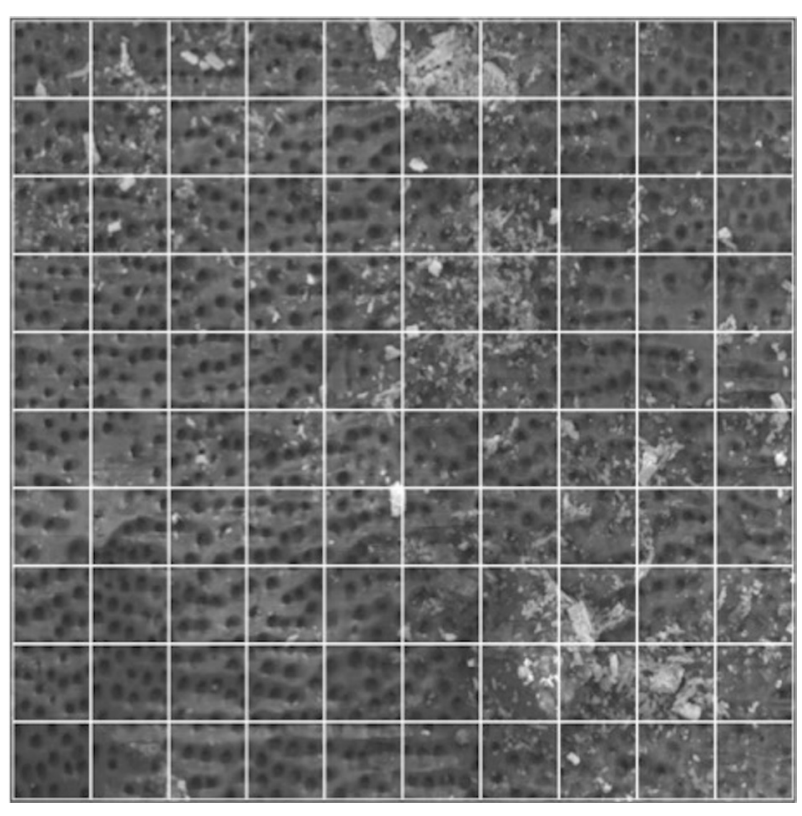

Figure 2. Representative preoperative image of a sample before irrigant activation with the digital grid overlapped that is used for quantification of clean areas. The picture shows that remnant filling material persisted in some areas after the reinstrumentation in the retreatment procedure. 


\section{Statistical analysis}

The Kappa test was applied to determine the interexaminer agreement. Preliminary analysis of data normality obtained using the Shapiro-Wilk and D'Agostino \& Person tests showed that the data were not normally distributed. The Wilcoxon test was used to analyze the percentage of clean areas before and after irrigation procedures in each group, MannWhitney $U$-test was used to compare removal of the filling material between the groups at the different levels, and Kruskal-Wallis was used to compare the removal of filling material between the three portions in the same group. The level of significance was set at $\mathrm{P}<0.05$, and Prisma 5.0 software (GraphPad Software Inc, La Jolla, USA) was used as the analytical tool.

\section{Results}

The interexaminer agreement was very high $($ kappa $=0.90)$.

Passive ultrasonic activation and continuous irrigant agitation with EasyClean significantly increased the removal of filling material $(\mathrm{p}<0.05)$ in all thirds of the root canal. The median, minimum and maximum values of percentage of cleanliness of the root canal walls in the apical, middle and cervical thirds are shown in Table 1.

No significant difference was observed in the performance of PUI and EC regarding the removal of residual filling material $(p>0.05)$. There was no

Table 1. Median, maximum and minimum values of the percentage of clean areas before and after irrigation procedures at different root canal levels.

\begin{tabular}{lccc}
\hline Group & Apical & Middle & Cervical \\
\hline US pre & $1(0-23)^{\mathrm{A}}$ & $7(0-40)^{\mathrm{A}}$ & $18(0-95)^{\mathrm{A}}$ \\
US post & $73(2-100)^{\mathrm{B}}$ & $87(42-98)^{\mathrm{B}}$ & $94(4-100)^{\mathrm{B}}$ \\
$\begin{array}{l}\text { Difference } \\
\text { pre-post US }\end{array}$ & $72(2-96)^{\mathrm{al}}$ & $74(37-90)^{\mathrm{al}}$ & $60(4-91)^{\mathrm{al}}$ \\
$\begin{array}{l}\text { EC pre } \\
\text { EC post }\end{array}$ & $77(0-24)^{\mathrm{A}}$ & $14(0-78)^{\mathrm{A}}$ & $4(0-95)^{\mathrm{A}}$ \\
$\begin{array}{l}\text { Difference } \\
\text { pre-post EC }\end{array}$ & $36(1-73)^{\mathrm{al}}$ & $48(19-100)^{\mathrm{al}}$ & $59(2-96)^{\mathrm{al}}$ \\
\hline
\end{tabular}

Different superscript capital letters in each column indicate statistical differences in the same group ( $p<0.05)$; Different superscript lowercase letters in each column indicate statistical differences between groups $(p<0.05)$; Different superscript numbers in each row indicate statistical differences in each row in root canal thirds $(p<0.05)$. difference in the removal of remnant filling material when comparing the apical, middle and cervical thirds in both PUI and EC groups ( $p>0.05)$.

\section{Discussion}

In nonsurgical retreatment, the complete removal of filling material is intended because when dentinal tubules are clean, intracanal medicaments and sealers may act more effectively in the root canal space., ${ }^{2,5}$

Nevertheless, to date, no retreatment protocol has provided complete filling material removal from the root canal. . $^{1,2,3,4,5,8,9,16}$ To overcome this clinical challenge, several supplementary treatments have been proposed to promote a better cleaning after reinstrumentation, such as the use of Self Adjusting File, ${ }^{1,25}$ laser irradiation, ${ }^{8}$ a NiTi instrument XP-endo Finisher ${ }^{4}$, and the use of ultrasonics and solvents. ${ }^{2,26}$ However, solvents tend to lead to more gutta-percha and sealer remnants on the root canal walls and inside dentinal tubules and should only be recommended if the working length cannot be achieved without a solvent. ${ }^{27}$ The use of PUI with $\mathrm{NaOCl}$ as a final step has also been recommended in retreatment because this procedure enhances the elimination of residual filling material, ${ }^{2,5,16}$ which is in agreement with the results of our study. In the present study, PUI was performed with $\mathrm{NaOCl}$ and EDTA because there was no intention of evaluating the chemical action of the solvent, only the mechanical action of the agitation devices. Despite these findings, no significant difference in removing filling residues after PUI has been reported. $3,22,28$

Some anatomical features may negatively influence the PUI performance, such as narrow and less tapered root canals. ${ }^{29,30}$ In teeth with canal curvatures, PUI has a lower efficacy compared to straight canals because when a curvature is present, the ultrasonic tip may touch the canal walls, restricting its vibratory motion and reducing ultrasonic action. ${ }^{31}$

Although mechanical activation of irrigants provides several benefits in root canal treatment, it has been reported that PUI promotes more effective cleaning of intermediate portions of the canal than that of the last few millimeters. ${ }^{18}$ On the contrary, a previous study ${ }^{5}$ showed that PUI improved the 
filling material removal including the apical third, demonstrating that the clinical use of ultrasonic activation is useful for removing filling material in retreatment. In this study, the removal of filling material residues was analyzed in the cervical, middle and apical third, and no significant difference was observed in the cleaning of the three portions. The apical enlargement during retreatment of the teeth in this experiment was performed using a ProDesign Logic 50/.01 instrument based on a previous study that showed a significant reduction in the amount of filling material in the apical area without weakening the tooth structure ${ }^{9}$. The effective cleaning of the apical curvature area in this study could have been caused by the fact that the apical enlargement of the canals was performed up to a size 50 , which created sufficient space for the ultrasonic tip (size 20) to vibrate freely in the irrigant. Previous studies also demonstrated better cleaning after PUI in wide and great tapered canals. ${ }^{29,30}$ Therefore, the clinical use of ultrasonic activation in retreatment may be suggested after root canal reinstrumentation with a suitable apical enlargement.

During ultrasonic irrigation, the tip of the instrument has the potential to cut canal walls during its activation. ${ }^{11,32}$ It may lead to accidents such as uncontrolled removal of dentin, canal deviation, apical zipping and even root perforation when an ultrasonic tip is activated in a curved canal. ${ }^{14,32}$ To prevent this from happening, the use of smooth wires is preferable. ${ }^{11}$ In this study, a non-cutting Irrisonic tip was used and placed in the center of the canal, avoiding touching the root canal walls. Recently, different mechanical non-cutting devices have also been developed. EasyClean is made of ABS plastic and presents minimum risk of deforming the canal walls, thus allowing its introduction up to the working length. ${ }^{18}$ The manufacturer suggests its use in reciprocating motion to avoid the instrument threading and consequent fracture. ${ }^{33}$ However, a recent study was conducted using EasyClean in continuous rotation at low speed, and the dentin debris were more efficiently removed from the root canal and isthmus area in mesial roots of mandibular molars ${ }^{20}$. In this study, the authors incorporated a continuous rotary motion in EC in an attempt to promote a vigorous irrigant agitation and increase removal of filling material that was attached to the root canal walls. EasyClean showed significant removal of filling material remnants after reinstrumentation, with no difference when compared to ultrasonic activation in all root canal thirds. Therefore, the null hypothesis was confirmed.

There is no consensus in the literature about the irrigation protocol required for effective irrigant activation in removing smear layer and debris from the root canal. Several irrigation protocols were also described in retreatment procedures. Muller et $\mathrm{al}^{28}$ used 60 seconds of PUI in teeth filled with AH Plus and gutta-percha, and reported that this time was insufficient to dislodge filling residues from the root canal walls. However, in the cited study, solutions were not replenished during or after ultrasonic activation. In the present study, the solution was activated by 3 cycles of 20 seconds, with the renewal of the irrigant, totaling 1 minute for each irrigant solution in both ultrasonics and EasyClean. The action of the 3 refreshment/activation cycles produces a cumulative effect and has been shown to be effective in removing additional dentin debris. ${ }^{10,18}$ Based on the results from the current and previous studies, ${ }^{5}$ this protocol seems to be useful in retreatment procedures as well because it improved the removal of residual filling material after reinstrumentation.

The use of environmental scanning electron microscopy in this investigation allowed the same sample to be analyzed before and after the irrigant activation procedure, which eliminates interferences of anatomical variations and characteristics of the dentin present in different specimens, resulting in a more consistent assessment of results. Owing to the possibility of acquisition of pre-and postoperative images, no control group was required for comparing the amount of filling material between groups. Furthermore, environmental scanning electron microscopy is a nondestructive method because the metallization process is not necessary unlike in conventional scanning electron microscopy imaging, which allows samples to be reused and evaluated in the same area. ${ }^{18,34}$

\section{Conclusions}

None of the agitation methods completely removed the residual filling material. Although the ultrasonic 
agitation favored greater area of removed material, the difference was not significant in relation to the EasyClean agitation.

\section{References}

1. Abramovitz I, Relles-Bonar S, Baransi B, Kfir A. The effectiveness of a self-adjusting file to remove residual gutta-percha after retreatment with rotary files. Int Endod J. 2012;45(4):386-92. https://doi.org/10.1111/j.1365-2591.2011.01988.x

2. Cavenago BC, Ordinola-Zapata R, Duarte MA, CarpioPerochena AE, Villas-Bôas MH, Marciano MA et al. Efficacy of xylene and passive ultrasonic irrigation on remaining root filling material during retreatment of anatomically complex teeth. Int Endod J. 2014;47(11):1078-83. https://doi.org/10.1111/iej.12253

3. Fruchi LC, Ordinola-Zapata R, Cavenago BC, Hungaro Duarte MA, Bueno CE, De Martin AS. Efficacy of reciprocating instruments for removing filling material in curved canals obturated with a single-cone technique: a micro-computed tomographic analysis. J Endod. 2014;40(7):1000-4. https://doi.org/10.1016/j.joen.2013.12.011

4. Alves FR, Marceliano-Alves MF, Sousa JC, Silveira SB, Provenzano JC, Siqueira JF Jr. Removal of root canal fillings in curved canals using either reciprocating single- or rotary multi-instrument systems and a supplementary step with the XP-endo finisher. J Endod. 2016;42(7):1114-9. https://doi.org/10.1016/i.joen.2016.04.007

5. Bernardes RA, Duarte MA, Vivan RR, Alcalde MP, Vasconcelos $B C$, Bramante CM. Comparison of three retreatment techniques with ultrasonic activation in flattened canals using microcomputed tomography and scanning electron microscopy. Int Endod J. 2015;49(9):890-7. https://doi.org/10.1111/iej.12522

6. Unal GC, Kaya BU, Taç AG, Keçeci AD. A comparison of the efficacy of conventional and new retreatment instruments to remove gutta-percha in curved root canals: an ex vivo study. Int Endod J. 2009;42(4):344-50. https://doi.org/10.1111/j.1365-2591.2008.01518.x

7. Rödig T, Hausdörfer T, Konietschke F, Dullin C, Hahn W, Hülsmann M. Efficacy of D-RaCe and protaper universal retreatment $\mathrm{NiTi}$ instruments and hand files in removing gutta-percha from curved root canals - a micro-computed tomography study. Int Endod J. 2012;45(6):580-9. https://doi.org/10.1111/j.1365-2591.2012.02014.x

8. Keleş A, Arslan H, Kamalak A, Akçay M, Sousa-Neto $M D$, Versiani MA. Removal of filling materials from ovalshaped canals using laser irradiation: a micro-computed tomographic study. J Endod. 2015;41(2):219-24. https://doi.org/10.1016/i.joen.2014.09.026

9. Rodrigues CT, Duarte MA, Almeida MM, Andrade FB, Bernardineli N. Efficacy of CM-wire, M-wire, and nickel-titanium instruments for removing filling

\section{Acknowledgments}

The authors deny any conflicts of interest. This work was supported by FAPESP (2015/03829-1). material from curved root canals: a micro-computed tomography study. J Endod. 2016;42(11):1651-5. https://doi.org/10.1016/i.joen.2016.08.012

10. Sluis LW, Vogels MP, Verhaagen B, Macedo R, Wesselink PR. Study on the influence of refreshment/activation cycles and irrigants on mechanical cleaning efficiency during ultrasonic activation of the irrigant. J Endod. 2010;36(4):737-40. https://doi.org/10.1016/i.joen.2009.12.004

11. Sluis LW, Versluis M, Wu MK, Wesselink PR. Passive ultrasonic irrigation of the root canal: a review of the literature. Int Endod J. 2007;40(6):415-26. https://doi.org/10.1111/j.1365-2591.2007.01243.x

12. Plotino G, Pameijer CH, Grande NM, Somma F. Ultrasonics in endodontics: a review of the literature. J Endod. 2007;33(2):81-95. https://doi.org/10.1016/i.joen.2006.10.008

13. Townsend C, Maki J. An in vitro comparison of new irrigation and agitation techniques to ultrasonic agitation in removing bacteria from a simulated root canal. J Endod. 2009;35(7):1040-3. https://doi.org/10.1016/i.joen.2009.04.007

14. Klyn SL, Kirkpatrick TC, Rutledge RE. In vitro comparisons of debris removal of the EndoActivator system, the $\mathrm{F}$ file, ultrasonic irrigation, and $\mathrm{NaOCl}$ irrigation alone after hand-rotary instrumentation in human mandibular molars. J Endod. 2010;36(8):1367-71. https://doi.org/10.1016/i.joen.2010.03.022

15. Munoz HR, Camacho-Cuadra K. In vivo efficacy of three different endodontic irrigation systems for irrigant delivery to working length of mesial canals of mandibular molars. J Endod. 2012;38(4):445-8. https://doi.org/10.1016/i.joen.2011.12.007

16. Grischke J, Müller-Heine A, Hülsmann M. The effect of four different irrigation systems in the removal of a root canal sealer. Clin Oral Investig. 2014;18(7):1845-51. https://doi.org/10.1007/s00784-013-1161-6

17. Topçuoğlu HS, Düzgün S, Ceyhanlı KT, Aktı A, Pala K, Kesim B. Efficacy of different irrigation techniques in the removal of calcium hydroxide from a simulated internal root resorption cavity. Int Endod J. 2015;48(4):309-16. https://doi.org/10.1111/iej.12316

18. Kato AS, Cunha RS, da Silveira Bueno CE, Pelegrine RA, Fontana CE, de Martin AS. Investigation of the efficacy of passive ultrasonic irrigation versus irrigation with reciprocating activation: an environmental scanning electron microscopic study. J Endod. 2016;42(4):659-63. https://doi.org/10.1016/i.joen.2016.01.016 
19. Alves FR, Almeida BM, Neves MA, Moreno JO, Rôças IN, Siqueira JF Jr. Disinfecting oval-shaped root canals: effectiveness of different supplementary approaches. J Endod. 2011;37(4):496-501. https://doi.org/10.1016/i.joen.2010.12.008

20. Duque JA, Duarte MA, Canali LC, Zancan RF, Vivan RR, Bernardes RA et al. Comparative effectiveness of new mechanical irrigant agitating devices for debris removal from the canal and isthmus of mesial roots of mandibular molars. J Endod. 2017;43(2):326-31. https://doi.org/10.1016/i.joen.2016.10.009

21. Rossi-Fedele G, Ahmed HM. Assessment of root canal filling removal effectiveness using micro-computed tomography: a systematic review. J Endod. 2017;43(4):520-6. https://doi.org/10.1016/i.joen.2016.12.008

22. Da Rosa RA, Santini MF, Cavenago BC, Pereira JR, Duarte MA, Só MV. Micro-CT Evaluation of root filling removal after three stages of retreatment procedure. Braz Dent J. 2015;26(6):612-8. https://doi.org/10.1590/0103-6440201300061

23. Hammad M, Qualtrough A, Silikas N. Threedimensional evaluation of effectiveness of hand and rotary instrumentation for retreatment of canals filled with different materials. J Endod. 2008;34(11):1370-3. https://doi.org/10.1016/j.joen.2008.07.024

24. Schneider SW. A comparison of canal preparations in straight and curved root canals. Oral Surg Oral Med Oral Pathol. 1971;32(2):271-5. https://doi.org/10.1016/0030-4220(71)90230-1

25. Solomonov M, Paqué $F$, Kaya $S$, Adigüzel $O$, Kfir $A$, Yiğit-Özer S. Self-adjusting files in retreatment: a highresolution micro-computed tomography study. J Endod. 2012;38(9):1283-7. https://doi.org/10.1016/j.joen.2012.06.019

26. Wilcox LR. Endodontic retreatment: ultrasonics and chloroform as the final step in reinstrumentation. J Endod. 1989;15(3):125-8. https://doi.org/10.1016/S0099-2399(89)80133-5
27. Horvath SD, Altenburger MJ, Naumann M, Wolkewitz M, Schirrmeister JF. Cleanliness of dentinal tubules following gutta-percha removal with and without solvents: a scanning electron microscopic study. Int Endod J. 2009 42(11):1032-8. https://doi.org/10.1111/j.1365-2591.2009.01616.x

28. Müller GG, Schönhofen AP, Móra PM, Grecca FS, Só MV, Bodanezi A. Efficacy of an organic solvent and ultrasound for filling material removal. Braz Dent J. 2013;24(6):585-90. https://doi.org/10.1590/0103-6440201302252

29. Lee SJ, Wu MK, Wesselink PR. The efficacy of ultrasonic irrigation to remove artificially placed dentine debris from different-sized simulated plastic root canals. Int Endod J. 2004;37(9):607-12. https://doi.org/10.1111/j.1365-2591.2004.00857.x

30. Sluis LW, Wu MK, Wesselink PR. The efficacy of ultrasonic irrigation to remove artificially placed dentine debris from human root canals prepared using instruments of varying taper. Int Endod J. 2005;38(10):764-8. https://doi.org/10.1111/j.1365-2591.2005.01018.x

31. Amato M, Vanoni-Heineken I, Hecker H, Weiger R. Curved versus straight root canals: the benefit of activated irrigation techniques on dentin debris removal. Oral Surg Oral Med Oral Pathol Oral Radiol Endod. 2011;111(4):529-34. https://doi.org/10.1016/j.tripleo.2010.11.002

32. Retsas A, Koursoumis A, Tzimpoulas N, Boutsioukis C. Uncontrolled removal of dentin during in vitro ultrasonic irrigant activation in curved root canals. J Endod. $2016 ; 42(10): 1545$-9. https://doi.org/10.1016/i.joen.2016.07.006

33. Easy Clean. EasyClean. Belo Horizonte; 2016 : [cited 2016 Dez 7]. Available from: http://www.easy.odo.br/ casos_clinicos/easy-clean-2/

34. Simezo AP, Bueno CES, Cunha RS, Pelegrine RA, Rocha DG, Martin AS et al. Comparative analysis of dentinal erosion after passive ultrasonic irrigation versus irrigation with reciprocating activation: an environmental scanning electron study. J Endod. 2017;43(1):141-6. https://doi.org/10.1016/i.joen.2016.09.016 